\title{
JOVENS MULHERES DO ÂMBITO RURAL: GÊNERO, PROJETOS DE VIDA E TERRITÓRIO EM FOTOCOMPOSIÇÕES
}

\author{
JÓVENES MUJERES DEL MEDIO RURAL: GÉNERO, PROYECTOS DE \\ VIDA Y TERRITORIO EN FOTOCOMPOSICIONES \\ YOUNG WOMEN IN THE RURAL CONTEXT: GENDER, LIFE PROJECTS \\ AND TERRITORY IN PHOTOCOMPOSITION
}

http://dx.doi.org/10.1590/1807-03102016v28n3p473

\author{
Adolfo Pizzinato, Cristiano Hamann, João Gabriel Maracci-Cardoso \\ Pontifícia Universidade Católica do Rio Grande do Sul, Porto Alegre/RS, Brasil \\ e Marcelo Moreira Cezar \\ Universitat Autònoma de Barcelona, Barcelona, España
}

\begin{abstract}
RESUMO
Este artigo analisa interfaces de gênero e território como marcadores identitários presentes nas falas e produções de imagens sobre projetos de vida de jovens mulheres de zonas rurais. O processo de pesquisa contemplou narrativas de caráter autobiográfico e fotocomposições realizadas pelas participantes, em que se buscou integrar aspectos de suas trajetórias acadêmicas, projetos vitais e profissionais, escolhas de vida e demandas culturais e comunitárias que influenciam no processo de construção de seus itinerários vitais. A aproximação a este grupo, comumente à margem da produção do saber em Psicologia, permitiu compreender como tais marcadores despontam de maneira dialógica em suas narrativas, questionando as formas de manifestação relacionadas aos antagonismos normativos entre o urbano/rural, o presente/passado, e das atribuições sociais ao ser mulher/ homem.
\end{abstract}

Palavras-chave: ruralidade; gênero; juventude; projetos de vida; fotocomposição.

\section{RESUMEN}

Este artículo analiza las interfaces entre género y territorio como marcadores identitarios que se encuentran presentes en las verbalizaciones e imaginario de los proyectos de vida de las mujeres rurales jóvenes. El proceso de investigación ha contemplado narrativas de carácter autobiográfico y fotocomposiciones realizadas por las participantes, donde se ha buscado integrar aspectos de sus trayectorias académicas, elecciones de vida, proyectos profesionales y demandas culturales y comunitarias, considerando la influencia de estos aspectos ejercen en el proceso de construcción de sus itinerarios vitales. La aproximación a este colectivo, que comúnmente se encuentra al margen de la producción de saber en psicología, ha permitido comprender cómo tales marcadores despuntan de manera dialógica en sus narrativas, cuestionando las formas en que se manifiestan en relación los antagonismos normativos urbano/rural, presente/pasado, y las atribuciones sociales de ser mujer/hombre.

Palabras clave: ruralidad; género; juventud; proyectos de vida; fotocomposición.

\begin{abstract}
This article analyzes the interface between gender and territory as identity markers present in the speeches and pictures about life projects of young women from rural areas. The research process included autobiographical narratives interviews and photo compositions made by the participants, which sought to integrate aspects of their academic trajectories, vital and professional projects, life choices and cultural and community demands that influence in the process of defining their vital projects. The approach to this group, often on the margins of production of knowledge in Psychology, allows us to understand how the identity markers emerge dialogically in their narratives, discussing the manifestations related to the normative antagonisms between urban/rural, present/past, and social assignments related to being woman/man.
\end{abstract}

Keywords: rurality; gender; youth; life projects; photocomposition. 


\section{Introdução}

Neste artigo analisam-se as caracterizações dos projetos de vida de jovens mulheres do âmbito rural, mediante a análise de narrativas autobiográficas integradas ao recurso da fotocomposição. Tais narrativas - entendidas como articulação de escolhas de vida num contexto de demandas culturais e comunitárias - permitem que se ponha em pauta a juventude enquanto palco de pertencimento e diferenciação, em que se estabelecem processos identitários diversos (Nascimento, 2006). Compreender a polissemia dos discursos que envolvem a vivência das participantes e suas composições identitárias possibilita que se contemple uma temática que classicamente marca a ideia de juventude como tempo e espaço social de transformação vital: o conceito de projeto de vida. Esse conceito é tomado no presente estudo como tensionador e lócus para a análise de marcadores identitários de jovens mulheres do contexto rural, de forma a facultar interpretações acerca das intersecções proporcionadas pelas vivências de juventude, feminilidade e ruralidade.

Um projeto de vida pode ser entendido como um conjunto de concepções pessoais que compõem idealizações sobre o que se espera ser ou realizar, estabelecendo relações com o meio através das possibilidades internas e externas de alcançar determinadas aspirações - projetadas para o futuro num exercício antecipatório (Velho, 2004). Considerando este espaço de aspirações de vida como constituição narrativa - numa tessitura em que despontam aspectos de gênero, territoriais, econômicos, educacionais, profissionais, etc - compreende-se tal processo de projeção ao futuro a partir de uma interpretação dialógica e contextual, numa relação de interlocução inerente à linguagem (Bakhtin, 1997). Neste processo de interlocução bakhtiniana - no qual o reconhecimento de si e do outro é entendido como indissociável formador do conceito de alteridade (Accorssi, Scarparo, \& Pizzinato, 2014) - se estabelece um espaço comunicacional de fronteira (Bakhtin, 1997). Esta noção de fronteira pode ser compreendida como processo dialógico, que pressupõe o estabelecimento de relações entre diversas formas de ser, como cruzamento de distintas vozes, posições e maneiras de ver o mundo, do mesmo modo que os projetos de vida enquanto criações e possibilidades de empoderamento na juventude (Arnett, 2007).

Para entender tais construções dialógicocontextuais, algumas categorias sociais podem servir de apoio analítico para a compreensão de processos tão subjetivos como a noção de si (ainda mais, em perspectiva temporal - presente, passado e futuro). A categoria gênero, por exemplo, permite discutir aspectos relacionados a masculinidades e feminilidades circunscritas em um contexto cultural, bem como as atribuições valorativas, hierárquicas e de poder que lhes acompanham. Strey (2001) aponta que categorias como gênero referem-se às expectativas e possibilidades inscritas na cultura, refutando o caráter essencialista da diferenciação entre homens e mulheres baseada em dicotomias biológicas. $\mathrm{O}$ gênero então poderia ser interpretado como a simbolização do corpo biológico através de sentidos de masculinidade e feminilidade disponíveis no discurso vigente, designando, em nosso contexto ocidental, significados possíveis para "ser homem" e "ser mulher" (Strey, 2001).

Meyer (2011) descreve que a vinculação das atribuições de gênero ao sexo biológico no Ocidente tem intrínseca relação com a emergência da concepção de família nuclear burguesa do século XVIII, onde se compreende a reprodução sexual como base de legitimação discursiva das formas de ser em sociedade. O despontar da noção de maternidade - em que se passa a exaltar o papel de mãe como inato às mulheres - por exemplo, tem sua origem neste período. Tal discurso atribui às mulheres a responsabilidade pela criação e cuidado dos filhos e, dessa forma, da continuidade e da moral da família e delimitação social do feminino ao âmbito doméstico (Guedes \& Daros, 2009). O cuidado e a maternagem, ligados ao trabalho reprodutivo,podem tornar-se um aprisionamento para as mulheres,distanciando-as de planos e sonhos que não contemplem esta forma tradicional de exercício do feminino (Guedes \& Daros, 2009).

Riscado e Peres (2008) ressaltam que os contextos culturais carregam modelos valorizados e desvalorizados do ser homem e ser mulher e que apontam a uma perspectiva hierárquica, que transcende o biológico, a um processo social que dá como pressuposto de dominação os atributos masculinos. Estas relações se mostram de maneira evidente em estudos como o de Paixão, Santos e Ramos (2008), os quais observaram que os jovens podem trazer valores tradicionais e hierarquizados das maneiras de ser homem e mulher, ao mesmo tempo que compartilham outros discursos acerca das formas de viver na contemporaneidade. A representação sobre o masculino e o feminino tradicionalmente estabelecidos explicita-se na dicotomia liberal do público/masculino/ produtivo e privado/feminino/reprodutivo, tornando as vivências de mulheres mais restritas com respeito às possibilidades de exercício de poder, tanto econômico quanto simbólico (Aboim, 2012). 
As relações destas práticas sociais repercutem em questionamentos sobre os projetos de vida, especialmente para as jovens. Um exemplo são as relações familiares, já que a influência da família no desenvolvimento vocacional, além de amplamente explorada, pode dar-se em diferentes níveis e intensidades. Essa influência pode acontecer tanto de uma forma mais indireta (uma vez que a situação socioeconômica e cultural da família influencia as aspirações educacionais e profissionais de seus membros), quanto de uma forma mais direta (quando os pais conversam, incitam ou limitam claramente as opções ocupacionais de seus filhos) (Magalhães, Alvarenga, \& Teixeira, 2012). Em leituras mais críticas no que concerne a discursos dominantes, o ingresso feminino no ensino superior (Barros, 2010), a constituição de um núcleo familiar (Lopes \& Soares, 2011) e o casamento (Wagner, Falcke, \& Meza, 1997) são aspectos claramente interseccionados com marcadores como gênero, classe, idade e território, por exemplo. Fatores como o casamento podem representar a manutenção de sistemas de poder - classicamente associados ao processo sucessório de bens e terras enquanto negociação entre homens e a submissão da mulher frente às demandas tradicionais do patriarcado, sobretudo no âmbito rural. Entretanto, com os movimentos contemporâneos de lutas pelos direitos da mulher, há uma redefinição e um questionamento, principalmente por parte dos jovens, de padrões e noções acerca do sistema familiar e das relações de gênero no núcleo familiar, movimento que também toca o espaço rural (Stropassolas, 2004).

Todavia, esse questionamento em relação às atribuições familiares e de gênero não se dá de maneira homogênea na cultura. Tais vivências devem ser contextualizadas e, neste sentido, seu impacto no âmbito rural se configura como especial alvo de interesse, com o intuito de desnaturalizar a usual dicotomia entre rural e urbano e a universalização dos padrões da urbanidade como hegemônicos, como o padrão humano. Tal dicotomia classificaria o espaço rural como aquilo que não é urbano, sendo definido, em especial, a partir de carências quanto ao modelo urbano e não às suas características (Carneiro, 1998). As problematizações destas concepções tradicionais de ruralidade aproximam-se mais de uma interpretação contemporânea de sujeito - distante da visão moderna que recorre a uma perspectiva nuclear e monológica de pessoa, como defende Hall (1998) - e permitem pensar o ser humano como permeado por diversas articulações discursivas que, mesmo possivelmente contraditórias, coexistem dialogicamente.
Existe uma série de associações dos espaços rurais com ideias de atraso (cultural, social, econômico, etc.) e isolamento (Silva, Dimenstein, \& Leite, 2013). Tais dados, muitas vezes se apoiam nas taxas de pobreza, baixa escolaridade e deficiência nas atenções governamentais e assistências em saúde no âmbito rural brasileiro (Pignatti \& Castro, 2010). Porém, há de se discutir sobre o quanto as referidas taxas apenas ilustram a falta de investimento governamental, mas reiteram este tipo de associação. Entre 2000 e 2010, por exemplo, cerca de 2 milhões de pessoas migraram do campo para as cidades, sendo que a metade era de jovens e, em maioria, mulheres, recrudescendo uma masculinização da população e da cultura rural (Menezes, Stropasola, \& Barcellos, 2014).

Considerando o âmbito rural não como território concreto, mas compreendido enquanto espaço de representação e de ação - permeado por elementos subjetivos - evidencia-se a necessidade de entender seus cotidianos contextuais. O cotidiano vivido nos territórios rurais traz consigo aspectos particulares para pensar as subjetividades aí constituídas. Alguns estudos já mostraram como os tipos de atividade neste contexto, principalmente no que tange ao meio familiar, são classificados de forma hierárquica com base nos pressupostos patriarcais (Brumer, 2004; Paulilo, 2004) - a exemplo dos trabalhos considerados leves, feitos por mulheres e crianças, e pesados, por homens (Paulilo, 1987).

Assim, longe de serem estáticas, as formas de significar suas vivências e planejar a vida dos jovens nestes contextos configuram redes de significados e modos de subjetivação complexos. Por meio de uma perspectiva bakhtiniana, essas vivências subjetivas podem ser vistas como formas de interlocução dialógicas, em que emerge a noção de eu/nós/eles compartilhados- de diferentes vozes, apropriações e reproduções discursivas (Bakhtin, 1997). Para dar ênfase às possibilidades de manifestações de tais diálogos, e ampliar o viés compreensivo das diferentes vozes e linguagens presentes nas narrativas das participantes, o presente estudo orienta-se para a utilização integrada de instrumentos de pesquisa como a fotocomposição e as entrevistas de caráter biográfico.

\section{Método}

Participaram da pesquisa 10 jovens de municípios de zonas rurais do Rio Grande do Sul, concluintes do ensino e médio com idade entre 15 e 18 anos, elencadas por conveniência em quatro municípios do Rio Grande 
do Sul/Brasil (Uruguaiana, Encruzilhada do Sul, Roca Sales e Ivorá). As participantes foram contatadas com a mediação das escolas rurais (ou que atendiam majoritariamente esse público) e a participação na pesquisa teve como premissa seu assentimento ou consentimento formal e a autorização dos responsáveis, registrados em Termos de Consentimento Livre e Esclarecido (TCLE) ou Termos de Assentimento, após aprovação do projeto de pesquisa no Comitê de Ética em Pesquisa da instituição docente dos pesquisadores.

Foi efetuada uma entrevista inicial com cada participante na qual se apresentava a proposta de estudo e se propunha a realização de uma produção fotográfica, além de uma segunda entrevista sobre o processo de criação e significação das fotografias. As entrevistas eram feitas com no mínimo uma semana e no máximo dez dias de intervalo, período que as participantes tinham para realizar uma série fotográfica estabelecida a priori. Utilizamos como recurso técnico câmeras fotográficas descartáveis com filme colorido, que possuem um número reduzido de fotos - em média 27 poses. Tal fato se mostrou importante, pois exigiu planejamento por parte das participantes e tornou possível a integração de eixos sintéticos de produção e discussão através da proposta de uma série organizada de possibilidades fotográficas, composta por eixos como: Escola; Família; Pai; Mãe; Futuro; Passado; Sonho; Profissão; Ser mulher; Ser homem; Casamento; Educação; Professor; Lazer; Onde você;mora; Cidade; Interior; Autorretrato.

Valer-se do uso da produção de imagens para compor esse cenário na vida das participantes deu-se por ser esta uma forma de produção cultural acessível e que possibilita suscitar diversas temáticas que não se explicitam facilmente no campo verbal, operando como um dispositivo narrativo. Tradicionalmente, a fotografia foi usada como ferramenta de pesquisa de caráter secundário e ilustrativo, cabendo às verbalizações o predomínio nas pesquisas em ciências humanas. A produ pe de imagens pode ser uma opção integrada com entrevistas, permitindo compreender melhor os processos de significação e sentidos sociais (Maurente \& Tittoni, 2007), da mesma maneira que possibilitaria entrar em contato com aspectos cotidianos. Assim, considerando o ato de fotografar como "operatividade ao exercício de autoria" (Maurente \& Maraschin, 2008, p. 42), ressalta-se poder compreender construções sobre o viver específico de jovens mulheres em contextos rurais, principalmente no tocante às noções de lugar, atribuições sociais e projetos de vida.

Tal aproximação metodológica se constituiu entendendo que a fotografia aperfeiçoa aspectos de expressão não tão diretamente apreensíveis pelo discurso verbal, da mesma forma que instrumentaliza o processo de construção/organização da entrevista narrativa (Maurente \& Tittoni, 2007; Pizzinato, 2008). Para a análise dos dados coletados - fotografias e entrevistas transcritas - foi utilizada a perspectiva dos Estudos Críticos do Discurso (Van Dijk, 2010). Esta perspectiva de estudo se caracteriza por uma visão transdisciplinar, na qual se destacam as relações e os abusos de poder como forma de compreender intersecções discursivas. Nesta pesquisa damos ênfase para questões de gênero e território como intersecções discursivas intrinsecamente relacionadas aos projetos de vida das jovens.

\section{Resultados e discussão}

A partir da análise discursiva realizada com base nas produções fotográficas e entrevistas com as jovens, estabeleceram-se três eixos de discussão: a diferenciação urbano/rural; discursos de de gênero em dicotomia e projetos de vida $\mathrm{e}(\mathrm{m})$ temporalidade: presente/passado/futuro. Tais eixos pareceram organizar os discursos das jovens em grande parte da sua produção, e permearam a sua composição em relação ao projeto de vida. Desta maneira, serão apresentados os resultados e as considerações desenvolvidas ao longo da análise, valendo-se de diferenciações trazidas pelas participantes em suas narrativas, como pode ser visualizado a seguir.

\section{A diferenciação urbano/rural}

A categoria compreende as definições dos espaços urbano e rural através de representações, ações e ligações afetivas com o território e suas possibilidades relacionais. Assim como em parte do discurso social, para algumas participantes o espaço rural é significado na relaificado $\mathrm{n}$ urbano, sendo o rural o espaço que carece de características do meio urbano tio meio "normal". Contudo, para outras, o que acontece épum processo inverso. As referidas jovens colocam o meio urbano como um espaço que carece de traços rurais, no que diz respeito, sobretudo, às relações afetivas, em certa idealização do espaço social rural.

Em entrevista com a participante Flávia ${ }^{l}$, podemos verificar como podem ser estabelecidas diferenciações em relação ao espaço urbano e rural: o campo é caracterizado por maior proximidade entre as pessoas, apesar da quantidade menor de sujeitos, enquanto a cidade denotaria uma falta de proximidade, apesar da quantidade grande de moradores: 
No campo é diferente, é mais aberto, as pessoas se comunicam mais, estão sempre juntas, se divertindo. Na cidade não. Eu acho que na cidade existe muito... as pessoas são mais... Distantes umas das outras, se comunicam pouco, o movimento é muito grande na cidade. As pessoas vão mais pelo emprego, todo mundo sai, até as famílias às vezes ficam distantes né, por causa do emprego na cidade. E aqui pra fora não. Aqui é mais calmo, as famílias estão sempre unidas. (Flávia, 14 anos,Uruguaiana)

Esta associação entre território e relações é acompanhada pela apresentação da vontade de estudar em grandes centros urbanos e a ambivalência em retornar ou não ao campo. Dentre os argumentos, destaca-se o desejo de obter outras experiências, outras possibilidades de exercício de si entendidas como incompatíveis com a ruralidade. Foi mencionado por algumas jovens que este processo é incentivado pelas famílias, apesar de geralmente não existir um suporte financeiro ou planejamento suficiente para tal. Estas ambivalências e desejos que coexistem para as jovens - entre viver oportunidades de educação na cidade e de constituir relações afetivas e familiares tidas como mais propícias no campo - podem ser indicativos de uma fragmentação dos processos identitários, concebidos como elementos característicos tanto do momento de vida como do tempo em que se encontram como ilustra a presença de discursos polissêmicos sobre si, de forma muito similar ao que acontece com jovens de outros espaços sociais (Nascimento, 2006).

Entretanto, a percepção de ter de sair do campo para a cidade com o intuito de fazer um curso universitário não é sem sentido, visto que estudos acadêmicos indicam não só a dificuldade de acesso a locais de ensino, como a defasagem do ensino superior quanto às demandas do âmbito rural b em relação, por exemplo, à formação oferecida que mostra deficiências no que concerne àcruralidade; falta de pesquisa acadêmica sobre o rural; e deficiência em questões como juventude e gênero no âmbito rural (Callou et al., 2008; Callou \& Silva, 2014). Além disso, a educação no contexto rural, não apenas a universitária, mas de forma geral, tem sido alvo de discussões. Nascimento (2011), por exemplo, pauta as alterações curriculares no palco das discussões sobre educação do campo, considerando como marcadores a noção de cidadania e a emancipação no contexto capitalista, marcadamente inspirados nas possibilidades de vida urbana.

\section{Discursos de gênero em dicotomia}

As formas de subjetivação de gênero parecem subjugadas à heteronorma da nossa cultura, que valoriza ou desvaloriza algumas possibilidades de exercício do ser homem e/ou ser mulher (Albano \& Carvalho, 2010; Riscado \& Peres 2008) e que em geral não questiona o aspecto performativo do exercício sexual/de gênero (Butler, 2003). As fotografias analisadas nas categorias propostas: "Ser homem" e "Ser mulher", especialmente, fomentam um maior contato com as noções de gênero vigentes no contexto das participantes, e se expressam de modo tradicional em atribuições claras e bem definidas, como ilustram as aqui selecionadas:

\section{Figura 1. Ser homem}

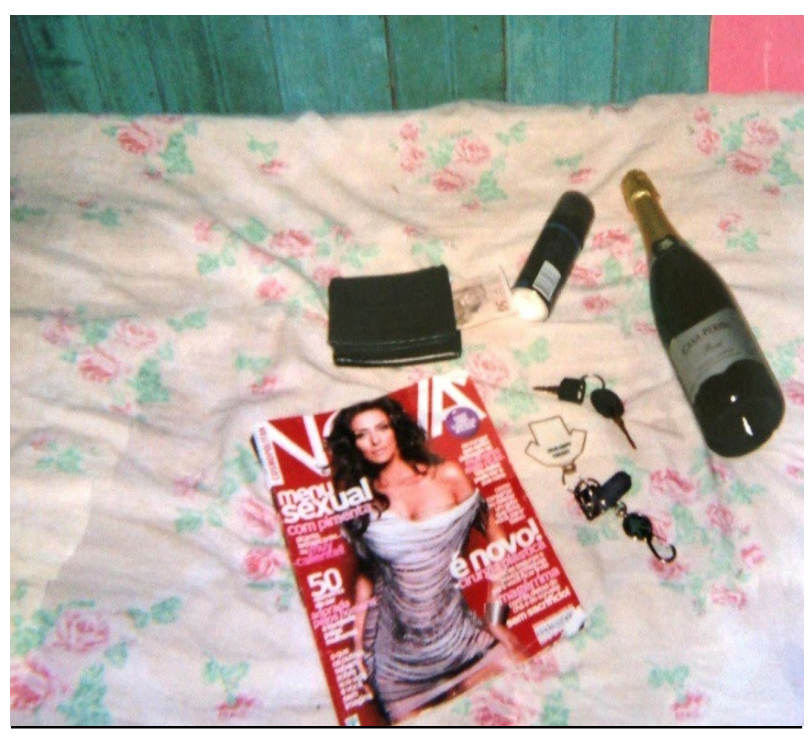

Foto da participante Verônica

Figura 2. Ser mulher

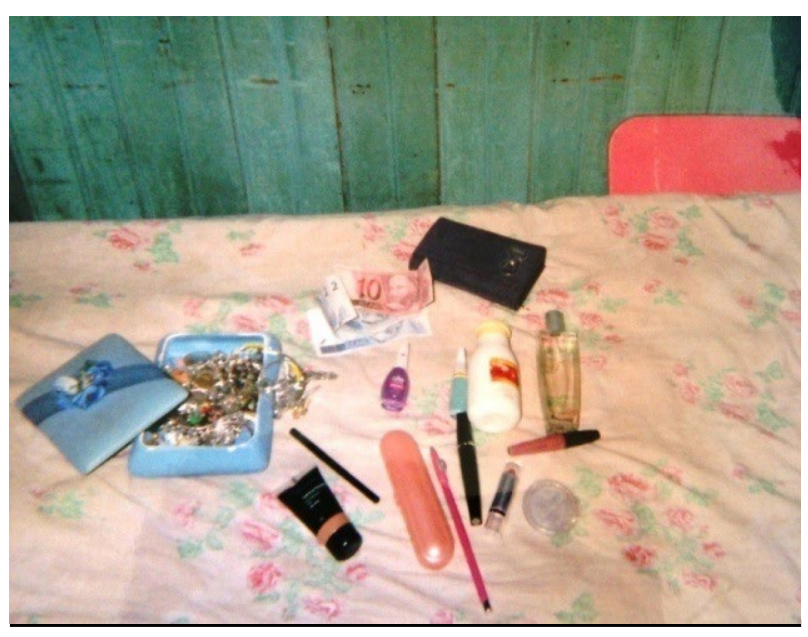

Foto da participante Verônica 
As distinções socialmente estabelecidas entre masculino e feminino se manifestam no cotidiano e se refletem também nas produções fotográficas das jovens, como, por exemplo, na composição da participante Verônica, em que "ser mulher" foi representado por uma nota de $\mathrm{R} \$ 10$, acompanhada de adereços estéticos e maquiagens; já "ser homem" por uma de R \$ 50, ao lado de uma garrafa de bebida alcoólica, chaves de um veículo, um perfume e uma revista com fotos de mulheres famosas e matérias intituladas, por exemplo, como: "menu sexual". Percebe-se a complementaridade das formas de representação de ser homem e ser mulher, no qual a figura feminina é objetificada.

O consumo do corpo feminino, a potência econômica e a referência à bebida e ao espaço público - expresso na primeira imagem com as chaves do carro, a garrafa, a revista e a nota de maior valor é complementado com uma segunda imagem que denota desvalorização econômica, e que não tem nenhuma referência direta ao espaço público, por mais que os itens de maquiagem possam permitir essa interpretação. $\mathrm{Na}$ entrevista subsequente à toma das fotografias, embora reconheça a importância da inserção da mulher no mundo do trabalho por questões financeiras, Verônica reitera o ser mulher à subordinação ao homem e o ganho financeiro como possibilidade de gerenciar a casa e seus atributos físicos.Verônica indica:

Pra mim mulher é ter independência, conseguir trabalhar pra sustentar a casa e não perder a pose de ser bonita ... acho que no fundo a gente quer ter esse dinheiro pra comprar, porque às vezes o marido dá o dinheiro pra pagar contas e não sobra quase nada pra gente se sentir bem, pra se sentir bonita. Acho que a gente tem que trabalhar também pra isso. Se a mulher quiser fazer uma plástica, guarda dinheiro pra poder fazer uma plástica! (Verônica, 15 anos, Uruguaiana)

Quando questionada sobre a diferença de valores entre as notas, Verônica retoma a hierarquia do gênero, afirmando que o dinheiro recebido por mulheres deve servir para recompensar o papel do homem como provedor:

Sim, de 50. Porque tem que ter no bolso, porque o homem gosta de proteger a mulher, porque a mulher gosta de ser independente, mas o homem... Eu li um livro uma vez que o homem gosta também de sustentar a mulher, porque dai ele vê que ela é frágil e ele gosta disso. Então, por isso que eu acho que deixa eles pagarem as contas da casa com o dinheiro deles e a gente trabalha pra nós, pra retribuir eles, então bota maquiagem e esses negócios. (Verônica, 15 anos, Uruguaiana)
Outras jovens apresentam uma série de discursos sociais que coexistem dialogicamente, evidenciando tanto as possibilidades contemporâneas de agência, como o trabalho no espaço público e formas de negociação no espaço privado, como reiteram atributos e funções tradicionais de gênero. Aboim (2012) relaciona as representações de masculinidade e feminilidade com a dicotomia liberal entre o público e o privado, em que as mulheres ficariam predominantemente no espaço doméstico com uma restrição do poder econômico e simbólico. De mesma forma, as fotografias sobre o feminino se restringiram quase que exclusivamente ao plano privado, referente ao trabalho doméstico e a questões de maternidade ou vaidade, simbolizadas por cosméticos e adereços estéticos. A masculinidade, por sua vez, foi representada pelo trabalho no âmbito público e primordialmente braçal e identificado com os fazeres tradicionais do meio rural - seja na lavoura, no trato aos animais, com tratores ou caminhões - e à socialização, referente ao comportamento externo ao lar (Aboim, 2012).

Destaca-se a produção da jovem Flávia na qual ela representou ser mulher por um autorretrato simulando uma gravidez. A condição feminina, assim, foi simbolizada reforçando a ideia da determinação do seu papel social como condicionado ao biológico reprodutivo, como contemplado pela jovem na entrevista:

Sempre que eu penso em mulher eu penso na minha mãe, em alguma mãe, não acho que necessariamente pra ser mulher tem que engravidar, mas toda mulher tem um sonho de ser mãe, é raro as que não têm esse sonho. Mas a maioria das pessoas, que não pode ter filho tem vontade de ter. Com certeza ela gostaria de ser mãe, de ter filhos, então quem não tem geralmente adota. (Fávia, 14 anos, Uruguaiana)

Ainda que haja uma maior autonomia para as mulheres decidirem sobre o desejo da maternidade, tal discurso está presente em algumas falas das jovens, perpassado por diversos discursos, construídos historicamente, e por vezes, conflitantes (Meyer, 2011; Paixão, Santos \& Ramos, 2008). Mesmo sendo entendida como possibilidade (e não como sentença), a maternidade e as funções do cuidado estão vinculadas aos papéis sociais e familiares ocupados pelas mulheres ao longo dos tempos, gerando uma grande influência nos planos de vida delas, o que implica que mesmo sendo uma escolha, a recusa à maternidade no projeto vital ainda deve ser muito justificada (Guedes \& Daros, 2009). 
Projetos de vida e(m) temporalidade: passado/ presente/futuro

Ainda que o norte das questões das entrevistas que se relacionavam à análise dos projetos de vida abrangesse suas expectativas para o término dos estudos, foi identificada uma dificuldade de materializar estrategicamente o direcionamento que as jovens entrevistadas dão para seus projetos de vida após a escolarização formal média. Nos questionamentos acerca dos sonhos ou planos futuros, as jovens relataram com frequência o desejo de término dos estudos escolares e o início de uma nova etapa acadêmica através do ingresso no Ensino Superior. A continuação dos estudos é acompanhada pelo plano de sair da cidade do contexto onde vivem, mesmo sem clareza dos condicionantes socioeconômicos que permitiriam a concretização desses planos.

A dificuldade de organização para a realização do plano de sair da cidade relaciona-se com a possibilidade que a continuidade nos estudos simboliza para as jovens na transição para a fase adulta. Tal transição, longe de ser estável, pode ser um processo caracterizado por certa multiplicidade identitária, na qual o adulto emergente vivencia papéis sociais diversos (Arnett, 2004, 2007). O processo de experimentação e exploração identitários gera instabilidades em campos como o financeiro, afetivo e social, demandando do jovem energia para lidar com diversas ambivalências.

Apesar de desejarem a independência social e financeira que os estudos podem propiciar, o rompimento ou o distanciamento com a família de origem e a passagem para um novo status social da fase adulta tornam esse processo bastante complexo e confuso para as jovens (Barros, 2010). Em um exemplo de tal configuração, a participante Débora fotografou um retrato de uma mulher segurando um diploma posicionado em cima de livros didáticos, com a justificativa: $O$ futuro eu imagino estudar $e$ me formar, por isso eu botei os livros e um diploma. Acho que esse éeo futuro que eu pretendo ter, estudar, me formar e talvez ter um emprego (Débora, 15 anos, Roca Sales). Quando questionada sobre o lugar onde pretende estudar e possíveis modos de realização do sonho, no entanto, referiu: Não tenho ideia ainda (Débora, 15 anos, Roca Sales). Apresenta-se, dessa forma, uma ambivalência entre a ideação de um projeto de vida e sua concretização, relacionada a um desconhecimento das diversas áreas de trabalho e à percepção de dificuldades socioeconômicas.

Foi recorrente nas verbalizações das participantes o incentivo dos pais e familiares em relação aos estudos, priorizando o bom desempenho e término da escola e ingresso no Ensino Superior. E embora o incentivo familiar, a maior fonte do sentimento de ambivalência dos jovens está na separação com a família e na assimilação da passagem para uma vida adulta e urbana (Barros, 2010). Nessa direção, podese exemplificar a entrevista com a jovem Laura, que finalizava a educação básica no momento e relatava: Minha mãe sempre se preocupou em me levar pra curso, coisas assim, e quando eu tava com dificuldade em alguma matéria ela pagava supervisão escolar pra mim, pra me ensinar. Ela sempre botou o colégio em primeiro lugar (Laura, 15 anos, Uruguaiana).

Tal perspectiva coincide com a fala de Jacira, que concluía o terceiro ano do Ensino Médio:

A mãe sempre me incentivou, o pai também, eles
sempre estão... A mãe é mais presente que o pai,
porque o pai trabalhava então ele não vinha muito no
colégio, mas ele sempre está perguntando como é que
eu estou na escola. Mas a mãe é mãe é mais presente,
porque ela está sempre vindo nas reuniões, esse tipo
de coisa. O pai não é muito de vir, entendeu, mas ele
sempre está perguntando como eu estou no colégio.
(Jacira, 15 anos, Uruguaiana)

Nesta citação, é importante observar como novamente surge o discurso social sobre os papéis de gênero, destacando a função de mãe como cuidadora e do pai como envolvido com trabalho concebido como produtivo (Alboim, 2012; Guedes \& Daros, 2009; Riscado \& Peres, 2008). Cabe ressaltar que as entrevistadas constituem a primeira geração de suas famílias a terminarem o Ensino Médio, fato que pode mostrar relação com a percepção de apoio apresentado pelos pais. A participante Laura indica que as dificuldades que os seus pais sofreram induzem o apoio que, hoje, eles dão para seus estudos: Pra ter um futuro melhor, né, não passar pelos que eles passaram, as dificuldades que eles tiveram. Eles querem um futuro melhor pra mim (Laura, 15 anos, Uruguaiana). Notase, aqui, uma vinculação à formação superior ao projeto de vida e uma associação entre as diferentes categorias discursivas aos projetos de futuro, retomando marcos identitários já consolidados e associando a formação superior a uma formação de self diferenciado em seu contexto, jádque as possibilidades no contexto rural ainda são identificáveis como excessivamente tradicionais e vinculadas ao âmbito doméstico/privado.

Outro elemento chave tanto nas fotografias quanto nas entrevistas, foi a vinculação do projeto de vida à formação de uma nucleação familiar. A aparente contradição entre o desejo pela formação de uma família e o afastamento desta como sentença social mostra uma temática na vida destas jovens carregada 
por discursos sociais tradicionais e possibilidades de empoderamento e subversão - que coexistem no espaço contemporâneo de forma dialógica. Contudo, é preciso enftizar que, mais do que uma escolha, tal elemento figura sempre nas falas como uma etapa a ser concluída ou justificada. Em perspectivas tanto clássicas como recentes de estudos de gênero, a constituição de uma família, o casamento, e a noção de cuidado, foram historicamente marcadores subjetivos intrinsecamente associados ao feminino (Scott, 1995). Neste estudo não emergiram diretamente elementos de sexualidade, no entanto, a percepção dos pesquisadores é que as discussões acerca das possibilidades de exercício sexual, para as participantes, estão baseadas em um formato heteronormativo que situa as possíveis subversões de gênero dentro de um palco heterossexual - e no que concerne principalmente às categorias casamento e família.

No tocante às expectativas profissionais, quando desvinculadas do ideal do trabalho doméstico ou da reprodução do modelo de trabalho do âmbito rural, a temática do cuidado está bastante presente, reforçando a noção de cuidado como uma tarefa de predomínio feminino, ligado a fazeres atribuidos historicamente às mulheres (Guedes \& Daros, 2009). Isto pode ser exemplificado pela escolha das jovens por carreiras universitárias como as de enfermagem, pedagogia, psicologia e, especialmente, medicina veterinária, como relata Fabiana:

tudo o que eu quero é fazer uma faculdade, sabe? Eu queria me formar em veterinária, mas eu penso assim, os animais não têm quem ajude eles, só o veterinário. Só que também eu penso em fazer enfermagem. Então eu daria prioridade pra enfermagem. (Fabiana, 16 anos, Uruguaiana)

Observa-se uma convergência entre a escolha profissional e as marcações de gênero, de modo que os projetos de vida sejam pautados, entre outros, pela posição socialmente designada ao feminino relacionada ao plano do cuidado. Escolhas referentes ao cuidado e à preocupação com o outro, retomam o lugar doméstico socialmente designado às mulheres, associando, assim, as duas categorias (Guedes \& Daros, 2009). Esta estratégia de acomodação deixa em aberto a possibilidade de construir um projeto vital que não rompa totalmente com as atribuições dicotômicas tradicionais de gênero nem com a possibilidade de retorno ao âmbito rural, pós-experiência urbana/ universitária.

Em muitas entrevistas, quando havia a menção de saída da comunidade para o curso superior em centros urbanos, logo - em tom de justificativa $m$ alguma afirmação de que tal saída seria temporária, pois depois de formadas certamente retornariam às suas comunidades. Assim, em muitas entrevistas houve ambivalência nas respostas, que se polarizaram entre a vontade de retorno à comunidade - situada como referencial afetivo - e a aspiração ao êxodo - desejo de seguir a vida em cidades maiores, relacionadas a mais possibilidades de emprego. A enunciação da jovem Angélica é expressiva pela representação da cidade grande como lugar de maiores possibilidades:

Eu penso que eu termino aqui, eu vou embora e só pretendo voltar pra ver meus pais. Não pretendo voltar pra cá pra morar ... Porque é, sei lá, é cidade pequena. Então, tipo... Emprego é meio pouco sabe? Então eu prefiro ir lá... Lá eu ajeito um emprego bom, faço a minha faculdade. Arrumo uma casinha boa e fico lá, não pretendo voltar. (Angélica, 15 anos, Ivorá)

A participante Jacira, por sua vez, explicita o desejo de permanecer morando em sua comunidade na vida adulta. Aspira viver na cidade para estudar mas, após, pretenderia retornar à sua comunidade rural: morar fora (cidade) só para fazer a escola agrícola, ou a veterinária... bem dizer eu nem vou ficar muito na cidade, eu vou ficar mais é no colégio né? (Jacira,15 anos, Uruguaiana). Na maioria das falas das participantes, a perspectiva de voltar para o campo é mais recorrente. A despeito da diversidade de posicionamentos, fica evidente como os marcadores educação formal e trabalho são importantes ao longo das narrativas de projeto de vida para as jovens e como a única justificativa aceitável para saírem mesmo que temporária e parcialmente - do território rural. Em suas falas denotam uma sensação de não pertencimento e temor das experiências na cidade, como nesta fala de Jacira: Eu me sinto mais à vontade aqui fora, na cidade eu me sinto perdida, eu acho aqui fora melhor, não gosto da cidade (Jacira, 15 anos, Uruguaiana).

Ainda sobre planos de futuro, houve verbalizações a respeito dos projetos no âmbito afetivo que suscitaram, principalmente, reflexões sobre o casamento que se destacaram no processo de fotocomposição. Algumas jovens relacionaram o tema com questões religiosas, como fotos compostas por duas alianças e a Bíblia ou fotos com capelas ou igrejas, apresentando perspectivas tradicionais acerca da instituição. Porém, também foi notável o número de respostas que faziam referência a uma intenção de não se casar.

Muitas jovens expunham suas opiniões sobre a instituição do casamento de maneira negativa ou secundária, destacando como prioridade seus estudos e projetos de carreira do que de fato o casamento ou a constituição de uma família nuclear própria. 
Assim, com a instituição "família", o casamento teve modificações na forma de percepção dos seus padrões e noções tradicionais. Expostas a modificações de acordo com a cultura, a sociedade e o processo histórico, tais instituições estão passando por períodos de grandes questionamentos, sobretudo por parte dos jovens acerca dos seus valores tradicionais, ocasionando momentos de tensão dentro destas (Vieira \& Stengel, 2010; Stropasolas, 2004). Mesmo assim, essas tensões se atenuam no contexto da pesquisa. A participante Flávia, por exemplo, compôs uma imagem de duas mãos se tocando, deixando em evidência as alianças nos dedos. No que tange à fotografia, ela refere:

geralmente quando tu vê uma mão com aliança, tu pensa: 'ah é casado'. Eu poderia também bater foto de uma família, porque eu acho que é união também é família. Quando eu penso no meu casamento eu me imagino de vestido de noiva. (Flávia, 14 anos,Uruguaiana)

A jovem Maria retratou a fotografia da cerimônia de sua irmã, na qual ela aparece usando um vestido branco. Na entrevista, entretanto, cita um descontentamento frente à visão tradicional socialmente compartilhada do casamento. Primeiramente, comenta sobre a passagem geracional da instituição: Minha irmã, minha mãe, é a mesma coisa, as duas são as mães, quem vê a gente acha que a minha irmã é minha mãe, minha mãe é minha avó e minha avó é minha bisavó (Maria, 14 anos, Roca Sales). Posteriormente, a mesma participante contesta a tradição da cerimônia, expondo a ambivalência entre a perspectiva familiar e o projeto de futuro:

Eu não penso em casar, pelo menos não tão cedo... Acho que a partir do casamento tu está formando a tua família, pode vir os filhos e netos. Sei lá, acho que casamento é bonito, só que é muito clássico, é tudo igual sempre. (Maria, 14 anos, Roca Sales)

A jovem Nádia, por outro lado, fotografou sua filha para representar o casamento, relacionando-o, a partir da entrevista, com noções de vida adulta e sua consequente responsabilidade. Ela justifica: Tirei porque depois do casamento vêm os filhos, vem mais responsabilidade... Antes eu pensava em sair, viajar, ir pra baile... Depois que veio a ' $G$ ', não dá pra fazer nada mais (Nádia, 17 anos, Uruguaiana). A condição da maternidade denota a transição do papel infantil para $o$ adulto, representando, assim, a perda de liberdade e o aumento da responsabilidade na vida de meninas adolescentes (Lopes \& Soares, 2011). Foi possível ver pelas fotos e entrevistas que na categoria casamento se estabeleceu uma relação intrínseca com a maternidade e constituição de um núcleo familiar tradicional e heteronormativo. Desta forma, mesmo que existisse a possibilidade de representação destes aspectos em outras seções propostas no trabalho fotográfico - ou outras formas de representação não heteronormativas ou tão tradicionais - se evidenciou, na grande maioria do material coletado, ou a naturalização dos papéis sociais tradicionais, ou a justificativa quando de escolhas que diferiam de tais discursos.

\section{Considerações finais}

Quando se trata do contexto rural vemos que, para além da falta de estudos em Psicologia, necessita-se de uma visão mais crítica em relação às dinamicidades do cotidiano e das formas de viver a juventude. Apesar de a vida no campo denotar relações da população com um território de características físicas específicas, muitas vezes marcado por grandes distâncias e número mais reduzido de cidadãos do que o das urbes, o fluxo massivo de informações veiculado pela globalização parece provocar muitos tensionamentos. Questões emergentes como as articulações entre o regional e o globalizado, os atravessamentos e as possibilidades de identificações que extrapolam a noção de território concreto, as novas configurações sociais de gênero a partir de feitos como os do feminismo e a concepção da juventude como historicamente situada, são alguns dos aspectos que colocam em pauta as particularidades contemporâneas de se viver no espaço rural.

Nesta pesquisa, foi possível perceber que os indicadores exibidos (como gênero, território, projetos de vida e juventude) são diretamente atravessados por discursos que sustentam papéis e possibilidades sociais. Os papéis de mulher/homem são representados com traços fortemente tradicionais e os territórios urbano/ rural possuem características dicotômicas, ainda que com certa crítica. Todavia, é importante destacar modificações e possibilidades de empoderamento das jovens quando estabelecem pontos de fuga do que seria esperado socialmente - a exemplo das possibilidades de escolha em relação à educação e casamento.

$O$ formato das escolhas $\mathrm{e}$ as formas de representação da vida das jovens participantes se mostram como possibilidade de criação e chamam a atenção para a necessidade de trabalhos que compreendam melhor as necessidades, demandas e formas de viver no âmbito rural - e em especial numa perspectiva que não vá pressupor intervenções ou análises a partir dos pressupostos do urbano. Há de se ressaltar ainda a necessidade de compreender melhor o impacto desta abordagem de pesquisa no contexto rural - e as possibilidades de mobilização que podem gerar pesquisas em que se interseccionam as questões abordadas nesse trabalho, principalmente se 
considerarmos a área da educação do campo. A leitura dos dados aqui construídos aponta a necessidade de rediscussão da educação no campo, em uma dimensão psicossocial. Aparentemente, a tendência à reprodução de fórmulas e valores de orientação hegemônicos e vinculados à cultura urbana ainda exerce um papel contundente na construção dos projetos vitais dessas jovens.

\section{Referências}

Aboim, S. (2012). Do público e do privado: uma perspectiva de gênero sobre uma dicotomia moderna. Revista Estudos Feministas, 20(1), 95-117.

Albano, R. M. \& Carvalho, M. V. C. (2010). O processo de construção da identidade de gênero de adolescentes: condutas e posturas sociais sinalizando diferenciações e desigualdades. In Anais do VI Encontro de Pesquisa em Educação da UFPI, O Pensamento Pedagógico na Contemporaneidade, Teresina: UFPI. Acesso em 20 de junho, 2015, em http://leg. ufpi.br/subsiteFiles/ppged/arquivos/files/VI.encontro.2010/ GT.15/GT 015 05 2010.pdf

Accorssi, A., Scarparo, H., \& Pizzinato, A. (2014). La dialogicidad como supuesto ontológico y epistemológico en Psicología Social: reflexiones a partir de la teoría de las representaciones sociales y la pedagogía de la liberación. Revista de Estudios Sociales, 50(n. spe.), 31-42.

Arnett, J. J. (2004). Emerging adulthood: a long and winding road from late teens trought the twenties. New York: Oxford University Press.

Arnett, J. J. (2007). Emerging adulthood: what is it, and what is it good for? Child Development Perspectives, 1(2), 68-73.

Bakhtin, M. (1997). A estética da criação verbal. São Paulo: Martins Fontes.

Barros, M. M. L. (2010). Trajetórias de jovens adultos: ciclo de vida e mobilidade social. Horizontes antropológicos, 16(34), 71-92.

Brumer, A. (2004). Gênero e agricultura: a situação da mulher na agricultura do Rio Grande do Sul. Revista Estudos Feministas, 12(1), 205-227.

Butler, J. (2003). Problemas de gênero: feminismo e subversão da identidade. Rio de Janeiro: Civilização Brasileira.

Callou, A. B. F., Pires, M. L. S., Leitão M. R. F. A., \& Santos, M. S. T. (2008). O estado da arte do ensino da extensão rural no Brasil. Revista Extensão Rural, 15(16), 84-115.

Callou, A. B. F. \& Silva, A. V. G. (2014). Comunicação e meio rural contemporâneo na formação universitária: a experiência da Universidade Federal Rural de Pernambuco - Brasil. Razón y Palabra, 87, 1-14.

Carneiro, M. J. (1998). Ruralidade: novas identidades em construção. Estudos Sociedade e Agricultura, 11, 53-75.

Guedes, O. S. \& Daros, M. A. (2009). O cuidado como atribuição feminina: contribuições para um debate ético. Serviço Social em Revista, 12(1), 122-134.

Hall, S. (1998). A identidade cultural na pós-modernidade. Rio de Janeiro: DP\&A.

Lopes, M. J. M. \& Soares, J. S. F. (2011). Biografias de gravidez e maternidade na adolescência em assentamentos rurais no Rio Grande do Sul. Revista da Escola de Enfermagem da USP, 45(4), 802-809.

Magalhães, M. O., Alvarenga, P., \& Teixeira, M. A. P. (2012). Relação entre estilos parentais, instabilidade de metas $\mathrm{e}$ indecisão vocacional em adolescentes. Revista Brasileira de Orientação Profissional, 13(1), 15-25.

Maurente, V. \& Maraschin, C. (2008). Experiência de si e autoria: articulações teóricas a partir de oficinas de fotografia digital em um serviço de saúde mental. Informática na educação: teoria \& prática, 11(2), 39-46.

Maurente, V. \& Tittoni, J. (2007). Imagens como estratégia metodológica em pesquisa: a fotocomposição e outros caminhos possíveis. Psicologia \& Sociedade, 19(3), 33-38.

Menezes, M., Stropasolas, V., \& Barcellos, S. (Orgs.). (2014). Juventude rural e politicas públicas no Brasil (Coleção Juventude: Série Estudos, n. 1). Brasilia, DF: Presidência da República.

Meyer, D. E. E. (2011). Corpo, gênero e maternidade: algumas relações e implicações com o cuidado em saúde. Enfermagem em foco, 2(1) 18-22.

Nascimento, I. P. (2006). Projeto de vida de adolescentes do ensino médio: um estudo psicossocial sobre suas representações. Revista Imaginário, 12(12), 55-80.

Nascimento, C. G. (2011). Educação do campo na encruzilhada entre emancipação versus reino do capital: uma leitura filosófica. Revista NERA, 14(18), 106-124.

Paixão, G. P. N., Santos, S. M. P., \& Ramos, P. R. (2008). Percepção das diferenças de gênero entre adolescentes do município de Juazeiro-BA. UDESC em Ação, 2(1), 1-12. Acesso em 20 de março, 2016, em http://www.revistas. udesc.br/index.php/udescemacao/article/view/1699/1347

Paulilo, M. I. S. (1987). O peso do trabalho leve. Revista Ciência Hoje, 5(28), 64-70.

Paulilo, M. I. S. (2004). Trabalho familiar: uma categoria esquecida de análise. Revista Estudos Feministas, 12(1), 229-252.

Pignatti, M. G. \& Castro, S. P. (2010). A fragilidade/resistência da vida humana em comunidade rurais do Pantanal Matogrossense (MT, Brasil). Ciências e Saúde Coletiva, 13(1), 83-94.

Pizzinato, A. (2008). Psicología e imágenes: el proceso de narración digital en la investigación sobre la identidad en la infancia en riesgo de exclusión. Hallazgos, 11, 55-64.

Riscado, L. \& Peres, S. O. (2008). Contribuição da categoria gênero para os estudos sobre adolescência e juventude no âmbito da psicologia e ciências sociais como meio de evidenciar a permanência das desigualdades e as necessidades de enfrentar a exclusão social. Revista Ártemis, 9, 77-91.

Silva, V. H. F, Dimenstein, M., \& Leite, J. F. (2013). O cuidado em saúde mental em zonas rurais. Mental, 10(19), 267-285.

Strey, M. N. (2001). Psicologia social contemporânea. Petrópolis, RJ: Vozes.

Stropasolas, V. L. (2004). O valor (do) casamento na agricultura familiar. Revista Estudos Feministas, 12(1), 253-267.

Van Dijk, T. (2010). Discurso e poder. São Paulo: Contexto.

Velho, G. (2004). Individualismo e cultura. Notas para uma antropologia da sociedade contemporânea. Rio de Janeiro: Jorge Zahar.

Vieira, E. D. \& Stengel, M. (2010). Os nós do individualismo e da conjugalidade na Pós-Modernidade. Aletheia, 32, 147160.

Wagner, A., Falcke, D., \& Meza, E. B. D. (1997). Crenças e valores dos adolescentes acerca de família, casamento, separação e projetos de vida. Psicologia: Reflexão $e$ Crítica, 10(1), 155-167. 


\section{Agradecimento}

À agência de fomento: CNPq, Edital PQ/2013.

Submissão em: 29/07/2015

Revisão em: 14/02/2016

Aceite em: 05/03/2016

Adolfo Pizzinato é doutor em Psicologia (Universitat Autònoma de Barcelona). Professor da Faculdade de Psicologia da PUCRS - Programa de Pós-Graduação em Psicologia.

Endereço: PUCRS, Escola de Humanidades, Programa de Pós-graduação em Psicologia, Av. Ipiranga, 6681, prédio
11, sala 930, CEP 90619-900. Porto Alegre/RS, Brasil.

E-mail: adolfopizzinato@hotmail.com

Marcelo Moreira Cezar é mestre em Psicologia Social (PUCRS) e doutorando em Psicologia Social (Universitat Autònoma de Barcelona). E-mail: marcelo.moreira.cezar@gmail.com

Cristiano Hamann é licenciado em História (ULBRA), mestre em Psicologia (PUCRS) e doutorando em Psicologia Social e Institucional (UFRGS). E-mail: chamann13@hotmail.com

João Gabriel Maracci-Cardoso é acadêmico de Psicologia da PUCRS.

E-mail: imaraccicardoso@gmail.com 